\title{
Provisórios em prótese fixa: revisão integrativa da literatura e técnicas para confecção
}

\author{
Temporary fixed dentures: integrative \\ literature review and techniques for confection
}

\section{Andressa Cristina da Silva Queiroz ${ }^{1}$ (D) Robson de Lima Gomes ${ }^{2}$ (1) Gregorio Marcio de Figueiredo Rodrigues ${ }^{3}$ (1) Viviane Maria Gonçalves de Figueiredo 4 (1)}

\author{
1-2Universidade Federal de Pernambuco (Recife).Pernambuco, Brasil. andressa.csqueiroz@ufpe.br, robson.lgomes@ufpe.br \\ 3Universidade Federal da Paraíba (João Pessoa). Paraíba, Brasil. gregorio_marcio1@yahoo.com.br \\ ${ }^{4}$ Autora para correspondência. Universidade Federal de Pernambuco (Recife). Pernambuco, Brasil. vivi_mfigueiredo@yahoo.com.br
}

\begin{abstract}
RESUMO | INTRODUÇÃO: A prótese fixa provisória é uma parte importante do tratamento reabilitador, sendo uma fase intermediária necessária para a confecção das próteses definitivas. OBJETIVO: Apresentar materiais e suas propriedades; como também as técnicas para confecção de provisórios em Prótese Fixa, através de uma revisão de literatura integrativa. MATERIAL E MÉTODO: Busca dos artigos ocorreu na BVS e PubMed, publicados em português e inglês, entre 2000 a 2020. A estratégia de busca utilizada foi utilizando as palavras chave: (Denture, Partial, Temporary) AND (Polymers) AND (Denture, Partial, Fixed) AND ("Dental Prosthesis" OR "Flexural Strength" OR "Dental Polishing"). Foram incluídos estudos completos disponíveis; abordando o tema provisórios em Prótese Parcial Fixa sobre dente. Os critérios de exclusão foram estudos de provisórios em prótese sobre implante, revisões de literatura e relatos de caso. Os dados completos dos textos selecionados foram extraídos pelos revisores. Técnicas foram apresentadas quanto às etapas de confecção. RESULTADOS: Os estudos abordaram a aplicação de diferentes materiais e técnicas, além das pesquisas laboratoriais serem prevalentes. Observou-se uma heterogeneidade entre objetos de estudos e variáveis, destacando-se o uso de distintos polímeros, técnicas e adição do reforço. CONCLUSÃo: Há diversos materiais para a confecção de provisórios. As técnicas relatadas foram o uso do molde em silicone, matriz em acetato e CAD/CAM, e as mais comuns de serem executadas na clínica diária foram adaptação da faceta de estoque (sobre o preparo e dente tratado endodonticamente), resina adaptada ou bolinha e molde ou matriz em silicone.
\end{abstract}

PALAVRAS-CHAVE: Prótese Parcial Temporária. Polímeros. Prótese Parcial Fixa. Resistência à Flexão. Prótese Dentária. Polimento Dentário.
ABSTRACT I INTRODUCTION: The temporary fixed denture is an important part of the treatment, being an intermediate phase necessary to manufacture the definitive denture. OBJECTIVE: Present materials and their properties, as well as the techniques for making provisionals in Fixed Prosthesis, through an integrative literature review. MATERIAL AND METHOD: Search for the articles in the BVS and PubMed, published in Portuguese and English, between 2000 and 2020. The search strategy used was: (Denture, Partial, Temporary) AND (Polymers) AND (Denture, Partial, Fixed) AND ("Dental Prosthesis" OR "Flexural Strength" OR "Dental Polishing"). The inclusion criteria were complete studies and available; studies of the temporary fixed denture on teeth. The exclusion criteria were studies of provisional prostheses on implants. The reviewers extracted the complete data of the selected texts. Techniques for temporary fixed denture were presented regarding the stages of preparation, literature reviews, and case reports. RESULTS: The studies addressed the application of different materials and techniques and laboratory research being prevalent. There was heterogeneity between study objects and variables, emphasizing the use of different polymers, techniques, and adding reinforcement. CONCLUSION: The revised literature presented several temporary materials. The techniques reported were the use of silicone mold, acetate matrix, and CAD / CAM. Moreover, the most common techniques to be performed in the daily clinic were an adaptation of the stock facet (on the prepared tooth and endodontically treated tooth), adapted resin or ball, and silicone mold or matrix.

KEYWORDS: Denture Partial Temporary. Polymers. Denture, Partial, Fixed. Flexural Strength. Dental Polishing. 


\section{Introdução}

A prótese fixa provisória é uma parte importante do tratamento reabilitador protético, pois desempenha um papel essencial no diagnóstico e plano de tratamento, sendo uma fase intermediária necessária para a confecção das próteses definitivas..$^{1-3}$ Ademais, essas restaurações são de grande valia para proteção do complexo dentina-polpa, além de função primária de preservar a saúde periodontal. ${ }^{4}$ Sua indicação é de curto a médio prazo, com temporização adequada de 1 a 2 semanas, podendo chegar até 6 meses de uso caso haja necessidade de uma abordagem cirúrgica.., 6

A qualidade de uma prótese fixa provisória depende de uma boa integridade marginal, rigidez e uma resistência adequada do material ${ }^{7}$, respeitando os requisitos biológicos, mecânicos e estéticos. ${ }^{1,2} \mathrm{~A}$ fratura desses provisórios é um contratempo desagradável para o paciente e o clínico, pois pode prejudicar o sucesso da fase de tratamento protético temporário e causar desconforto ao paciente. ${ }^{8}$ Reparos no provisório consomem tempo e apresentam custo elevado. 9 Devido a essa possibilidade de fratura, se busca elevar a resistência à fratura de provisório para prótese fixa para áreas de alto estresse oclusal a partir de reforçamento com fibras..$^{10}$

Entre os materiais estudados para confecção desses reforços com fibras, têm-se: fibras de vidro, carbono, fibra de aramida e polietileno. ${ }^{8}$ E para a confecção dos provisórios usa-se frequentemente polímeros baseados em poli metacrilato de metila (PMMA), poli metacrilato de etila (PEMA) ou n-poli metacrilato de butila (PBMA). $\cdot 11$

Para alcançar o sucesso clínico do provisório, além de observar o material a ser utilizado, deve ser considerada a geometria dos preparos dentais, mudanças de temperatura e saliva durante a confecção dos provisórios pela técnica direta, pois podem influenciar nas propriedades dos provisórios A saliva pode influenciar na técnica direta de confecção 9 , porém é menos comum em prótese provisória extensa. Assim como a resposta periodontal aos materiais escolhidos, como a presença de gengivite, a resposta periodontal negativa está mais relacionada à inadequada técnica de confecção (adaptação marginal e acabamento/polimento) que ao material escolhido. $\frac{12}{}$

Referente às técnicas para confecção de coroas provisórias, têm-se as diretas, híbrida e indireta. ${ }^{4}$
Nos últimos anos, o avanço da tecnologia de CAD/CAM (design auxiliado por computador / computador a tecnologia de manufatura assistida) tem auxiliado na confecção dessas coroas provisórias, representando uma importante conquista na área de prótese dentária. ${ }^{13}$

Estudos que representem evidências científicas sobre provisórios em prótese fixa, quanto à escoIha e propriedades do material e suas técnicas de confecção, são escassos na literatura. Há uma lacuna científica de artigos que sumarizem essas informações para o cirurgião-dentista, de modo que possam auxiliá-lo a realizar as tomadas de decisões clínicas; bem como orientar este profissional na confecção passo a passo da prótese provisória, por ser limitada esta informação até mesmo em livros didáticos. Com base no exposto, o estudo teve por objetivo apresentar materiais e suas propriedades; como também as técnicas para confecção de provisórios em Prótese Fixa, através de uma revisão de literatura integrativa.

\section{Metodologia}

\section{Método}

Revisão Integrativa da literatura que sintetiza as pesquisas disponíveis sobre a temática, confecção de provisório em Prótese Fixa, e direciona a prática fundamentando-se em conhecimento científico.

\section{Critério de elegibilidade}

A presente revisão da literatura apresentou como estratégia de busca nas bases de dados: Biblioteca Virtual em Saúde (BVS) https://bvsalud.org/; Pubmed https://pubmed.ncbi.nlm.nih.gov/, publicados em português e inglês, entre 2000 a 2020, sendo a última pesquisa realizada em 3 de dezembro de 2020. Os descritores utilizados foram: (Denture, Partial, Temporary) AND (Polymers) AND (Denture, Partial, Fixed) AND ("Dental Prosthesis" OR "Flexural Strength" OR "Dental Polishing").

Os critérios de inclusão neste trabalho foram estudos com artigos completos disponíveis; estudos de provisórios em Prótese Parcial Fixa sobre dente. Os critérios de exclusão foram: estudos de provisórios em prótese sobre implante, revisão de literatura e relato de caso. 


\section{Seleção do estudo}

Os títulos e resumos de todos os trabalhos foram analisados por três revisores. Todos estudos que preencheram os critérios de inclusão foram selecionados para leitura do texto completo e incluídos para extração dos dados, enquanto foram registradas as razões para a exclusão. A estratégia de busca da pesquisa está detalhada na Figura 1.

\section{Extração dos dados}

Os dados completos dos textos selecionados foram extraídos pelos revisores. A coleta de dados foi baseada nos resultados sobre confecção de provisórios em Prótese Fixa.

\section{Análise de dados}

Os dados foram coletados e incluídos no Quadro 1, a extração dos dados das pesquisas incluídas foi feita através da criação de tabela padronizada no Excel com as seguintes informações: autor e ano de publicação, objetivo, tipo de estudo e país em que a pesquisa aconteceu, nível de evidência científica, metodologia, informações sobre a confecção do provisório e resultados. O nível de evidência científica foi baseado na classificação do Oxford Centre for Evidence- based Medicine, citada no artigo de Demathé et al. ${ }^{14}$ A extração de todos os dados foi realizada pelos três revisores, e a partir dos dados obtidos, foram criadas tabelas a fim de sumarizar os dados.

\section{Técnicas para Confecção de Provisórios}

Técnicas diretas e indireta para provisórios serão apresentadas quanto as etapas de confecção. Além do uso de provisórios confeccionados pela técnica do CAD/CAM.

\section{Resultados}

Esta revisão de literatura foi pautada em técnicas diretas para confecção de provisório em Prótese Fixa. A seleção resultou em 6 estudos de pesquisa sobre o tema, a Figura 1 exemplifica a seleção da literatura na base de dados da PUBMED e BVS, além dos critérios de exclusão já comentados. A PUBMED apresentou inicialmente 3 artigos e a BVS 7 artigos que, posteriormente, passaram pelos critérios de inclusão e exclusão, resultando no total de 6 artigos incluídos nesta revisão. Todos os estudos revisados estão contemplados no Quadro 1. Ao total, foram incluídos 2 estudos clínicos e 4 estudos laboratoriais.

Figura 1. Bases de dados, artigos incluídos, artigos excluídos para a revisão da literatura

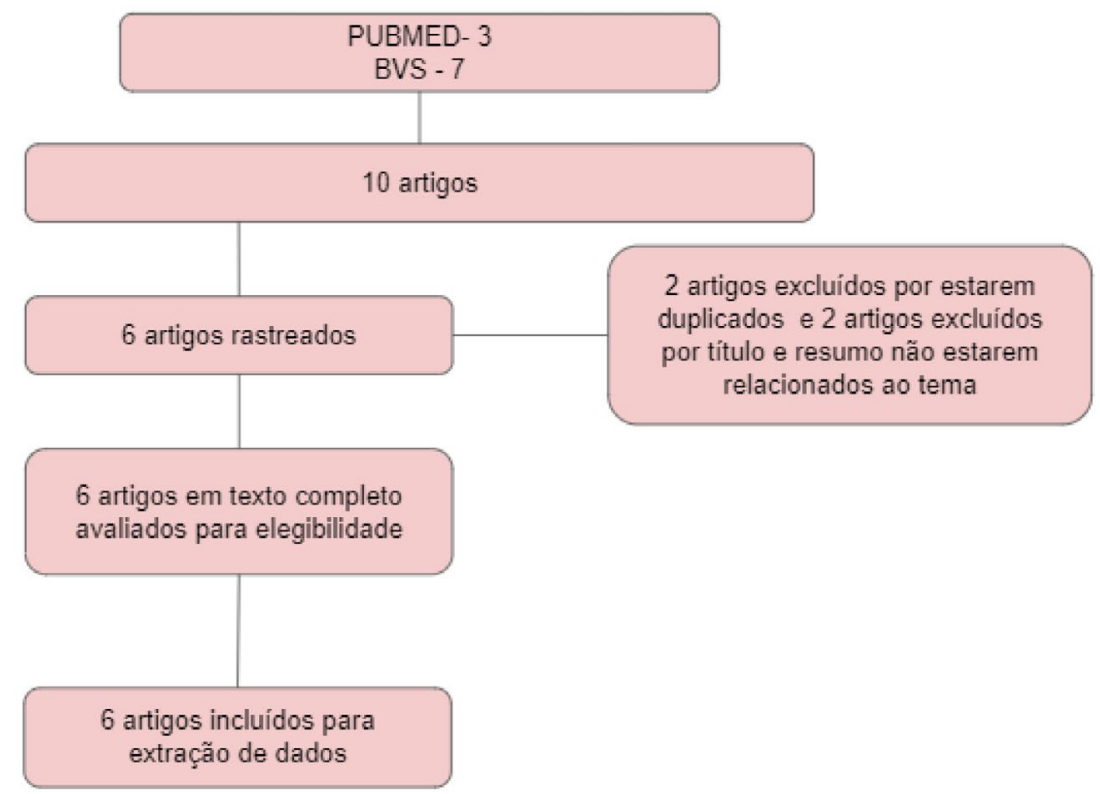

Fonte: Os autores (2021). 
Quadro 1. Autor (ano), Objetivo, Tipo de estudo (Nível de Evidência - NE), Material para provisório, Reforço, Metodologia, Técnica para confecção do provisório e Resultados (continua)

\begin{tabular}{|c|c|c|c|c|c|c|}
\hline $\begin{array}{l}\text { Autor } \\
\text { (ano) }\end{array}$ & Objetivo & $\begin{array}{l}\text { Tipo de estudo } \\
\text { (NE) }\end{array}$ & $\begin{array}{l}\text { Material para } \\
\text { provisório }\end{array}$ & Metodologia & $\begin{array}{l}\text { Técnica para confecção do } \\
\text { provisório }\end{array}$ & Resultados \\
\hline $\begin{array}{l}\text { Luthardt et } \\
\text { al. }^{12}\end{array}$ & $\begin{array}{l}\text { Comparar o manuseio, } \\
\text { adaptação, aderência de } \\
\text { placa, gengivite e } \\
\text { estabilidade de cor entre } 4 \\
\text { materiais para fabricação } \\
\text { de coroas provisórias } \\
\text { Avaliação subjetiva do } \\
\text { paciente e do profissional; }\end{array}$ & $\begin{array}{l}\text { Ensaio clínico } \\
\text { randomizado } \\
\text { (1B) }\end{array}$ & $\begin{array}{l}\text { Autopolimerizável } \\
\text { (bis-acrílcia) } \\
\text { Dupla Cura } \\
\text { Fotopolimerizável }\end{array}$ & $\begin{array}{l}30 \text { pacientes com } \\
\text { necessidades de coroas } \\
\text { unitárias, coroas } 3 / 4 \text { ou pontes } \\
\text { fixas. } \\
\text { Cada paciente foi tratado com } \\
\text { uma restauração } \\
\text { autopolimerável temporária } \\
\text { (controle) e um outro material, } \\
\text { em teste, selecionado } \\
\text { aleatoriamente. } \\
\text { O tempo médio de tratamento } \\
\text { foi de } 37,5 \text { dias e as } \\
\text { restauraçães foram } \\
\text { confeccionadas com auxílio de } \\
\text { matriz em acetato. }\end{array}$ & $\begin{array}{l}\text { Todas as restaurações foram } \\
\text { feitas com uma matriz em } \\
\text { acetato; } \\
\text { Corte: as restaurações } \\
\text { temporárias foram cortadas com } \\
\text { cortadores HM finos; } \\
\text { Polimento: a partir de polidores } \\
\text { de silicone (mecânico) e uso de } \\
\text { cimento provisório. }\end{array}$ & $\begin{array}{l}\text { O índice de placa foi maior sobre as } \\
\text { restaurações temporárias que no dente } \\
\text { adjacente natural. O índice de sangramento } \\
\text { gengival não apresentou mudança } \\
\text { significante; } \\
2 \text { casos apresentaram descoloração } \\
\text { insatisfatória; } \\
\text { Falhas de tratamento ocorreram em } 4 \text { casos } \\
\text { com avaliações inaceitáveis de integridade, } \\
\text { rachaduras e lascamento marginal; } \\
\text { Os pacientes avaliaram os materiais como } \\
\text { satisfatórios; } \\
\text { Propriedades mecânicas (integridade, } \\
\text { pontos de contato oclusais e espaçamento } \\
\text { interdental) das resinas acrílicas de dupla } \\
\text { cura e fotopolimerizável são vantajosas, } \\
\text { porém manuseio é dificultoso. }\end{array}$ \\
\hline $\begin{array}{l}\text { Nohrstrom; } \\
\text { Vallittu; } \\
\text { Urpo }^{15}\end{array}$ & $\begin{array}{l}\text { Determinar a influência do } \\
\text { posicionamento, } \\
\text { quantidade de fibras } \\
\text { usadas como reforço na } \\
\text { resistência à fratura de } \\
\text { provisórios com diferentes } \\
\text { comprimentos }\end{array}$ & $\begin{array}{l}\text { Estudo } \\
\text { laboratorial } \\
(2 \mathrm{C})\end{array}$ & $\begin{array}{l}\text { Autopolimerizável } \\
\text { (convencional) }\end{array}$ & $\begin{array}{l}\text { Espécimes em formato de } \\
\text { ponte fixa foram envelhecidos } \\
\text { artificialmente (armazenagem } \\
\text { em água), em seguida testado } \\
\text { a resistência à fratura }\end{array}$ & $\begin{array}{l}\text { Impressão dos dentes pilares foi } \\
\text { feita com polivinilsiloxano. } \\
\text { A resina foi misturada à mão } \\
\text { durante } 15 \text { segundos e depois } \\
\text { foi vertida no molde. } \\
\text { O reforço de fibra de vidro } \\
\text { unidirecional foi cortado em } \\
\text { comprimento predeterminado } \\
\text { de acordo com o grupo de } \\
\text { provisório estudado. }\end{array}$ & $\begin{array}{l}\text { A carga necessária para fraturar os } \\
\text { provisórios não reforçados variou de } 372 \text { a } \\
1061 \mathrm{~N} \text {. A carga média de fratura para os } \\
\text { provisórios reforçados variou de } 508 \text { a } 1296 \\
\mathrm{~N} \text {, condição esta que foi estatisticamente } \\
\text { significativa. } \\
\text { O comprimento do vão e a quantidade de } \\
\text { fibras afetam significativamente a carga de } \\
\text { fratura. Ao alongar a extensão do } \\
\text { provisório, o efeito do reforço da fibra de } \\
\text { vidro torna-se mais necessário. }\end{array}$ \\
\hline Lang et al. ${ }^{9}$ & $\begin{array}{l}\text { Comparar a resistência à } \\
\text { fratura de vários materiais } \\
\text { de prótese parcial fixa } \\
\text { provisória em um } \\
\text { ambiente oral artificial }\end{array}$ & $\begin{array}{l}\text { Estudo } \\
\text { laboratorial } \\
(2 \mathrm{C})\end{array}$ & $\begin{array}{l}\text { Autopolimerizável } \\
\text { (bis-acrílica e } \\
\text { convencional) }\end{array}$ & $\begin{array}{l}\text { Espécimes em formato de } \\
\text { ponte fixa foram envelhecidos } \\
\text { artificialmente (térmico e } \\
\text { mecânico), em seguida testado } \\
\text { a resistência à fratura }\end{array}$ & $\begin{array}{l}\text { Todos os provisórios foram } \\
\text { fabricados usando um molde de } \\
\text { silicone e cimentação provisória. }\end{array}$ & $\begin{array}{l}\text { O grupo controle da Protemp } 3 \text { Garant } \\
\text { mostrou uma resistência mediana à fratura } \\
(1015 N) \text {, duas vezes maior que dos outros } \\
\text { materiais. } \\
\text { Todas as } 10 \text { amostras feitas de Cronsin e } \\
\text { Trim falharam durante o envelhecimento, e } \\
\text { todas as } 10 \text { amostras de Tempofit falharam } \\
\text { devido a fratura. } \\
\text { Protemp Garant e Luxatemp mostraram } \\
\text { melhores resistências à fratura (resinas bis- } \\
\text { acrílicas). }\end{array}$ \\
\hline
\end{tabular}


Quadro 1. Autor (ano), Objetivo, Tipo de estudo (Nível de Evidência - NE), Material para provisório, Reforço, Metodologia, Técnica para confecção do provisório e Resultados (continuação)

\begin{tabular}{|c|c|c|c|c|c|c|}
\hline $\begin{array}{l}\text { Autor } \\
\text { (ano) }\end{array}$ & Objetivo & $\begin{array}{l}\text { Tipo de estudo } \\
\text { (NE) }\end{array}$ & $\begin{array}{l}\text { Material para } \\
\text { provisório }\end{array}$ & Metodologia & $\begin{array}{c}\text { Técnica para confeç̧ão do } \\
\text { provisório }\end{array}$ & Resultados \\
\hline $\begin{array}{l}\text { Pfeiffer; } \\
\text { Grube }^{10}\end{array}$ & $\begin{array}{l}\text { Avaliar a carga de fratura } \\
\text { para provisórios feitos em } \\
\text { diferentes materiais e } \\
\text { alturas de pônticos. }\end{array}$ & $\begin{array}{l}\text { Estudo } \\
\text { Laboratorial } \\
(2 \mathrm{C})\end{array}$ & $\begin{array}{l}\text { Autopolimerizável } \\
\text { (convencional) } \\
\text { Termoplástica } \\
\text { Resinas associadas a } \\
\text { fibras para reforço }\end{array}$ & $\begin{array}{l}\text { Espécimes em formato de } \\
\text { ponte fixa foram envelhecidos } \\
\text { artificialmente } \\
\text { (termociclagem), em seguida, } \\
\text { testado a resistência à fratura }\end{array}$ & $\begin{array}{l}\text { Para alcançar a reprodução mais } \\
\text { exata possivel da prótese parcial } \\
\text { fixa padrão, foi usado um } \\
\text { procedimento de duplicação das } \\
\text { peças de níquel-cromo com } \\
\text { moldes de silicone e uso de } \\
\text { cimentação provisória. }\end{array}$ & 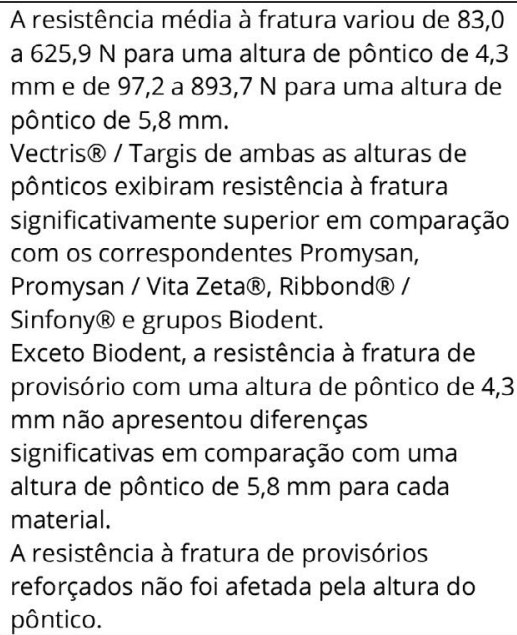 \\
\hline $\begin{array}{l}\text { Geerts; } \\
\text { Overturf; } \\
\text { Oberholzer }^{8}\end{array}$ & $\begin{array}{l}\text { Comparar a tenacidade à } \\
\text { fratura de um } \\
\text { polimetilmetacrilato } \\
\text { (PMMA) e resina bis-acrílica } \\
\text { (BAC) reforçada com fio de } \\
\text { aço inoxidável, fibra de } \\
\text { vidro e fibra de polietileno. }\end{array}$ & $\begin{array}{l}\text { Estudo } \\
\text { laboratorial } \\
(2 \mathrm{C})\end{array}$ & $\begin{array}{l}\text { Autopolimerizável } \\
\text { (bis-acrílcia e } \\
\text { convencional) }\end{array}$ & $\begin{array}{l}\text { Espécimes em formato de } \\
\text { barra foram testados quanto a } \\
\text { resistência à fratura, teste de } \\
\text { flexão de } 3 \text { pontos. }\end{array}$ & $\begin{array}{l}\text { Um molde de aço inoxidável } \\
\text { feito sob medida foi usado para } \\
\text { produzir amostras padronizadas. } \\
\text { Os espécimes de resina PMMA } \\
\text { foram polimerizados por } 20 \text { min } \\
\text { no molde e mais } 10 \text { minutos na } \\
\text { bancada. As amostras de resina } \\
\text { BAC foram polimerizadas por } 10 \\
\text { minutos no molde e } 5 \text { minutos } \\
\text { adicionais em bancada. Ambos } \\
\text { consideraram o dobro do tempo } \\
\text { recomendado pelos fabricantes. } \\
\text { As bordas das amostras foram } \\
\text { acabadas com papel carboneto } \\
\text { de grão } 1000 \text {. } \\
\text { Com exceção do grupo controle, } \\
\text { foi inserido material de reforço } \\
\text { paralelamente ao longo eixo das } \\
\text { amostras. }\end{array}$ & $\begin{array}{l}\text { O grupo controle de resina PMMA } \\
\text { apresentou tenacidade à fratura } \\
\text { significativamente menor do que para } \\
\text { resina BAC. } \\
\text { Fibras de vidro e reforços de fio de aço } \\
\text { inoxidável produziram resistência à fratura } \\
\text { significativamente maior para PMMA e BAC. } \\
\text { Não havendo diferença significativa entre a } \\
\text { tenacidade à fratura do fio e da fibra de } \\
\text { vidro para ambos materiais provisórios. } \\
\text { Fibras de polietileno não apresentaram } \\
\text { tenacidade à fratura significativa como os } \\
\text { outros reforços supracitados. }\end{array}$ \\
\hline
\end{tabular}


Quadro 1. Autor (ano), Objetivo, Tipo de estudo (Nível de Evidência - NE), Material para provisório, Reforço, Metodologia, Técnica para confecção do provisório e Resultados (conclusão)

\begin{tabular}{|c|c|c|c|c|c|c|}
\hline $\begin{array}{l}\text { Autor } \\
\text { (ano) }\end{array}$ & Objetivo & $\begin{array}{l}\text { Tipo de estudo } \\
\text { (NE) }\end{array}$ & $\begin{array}{l}\text { Material para } \\
\text { provisório }\end{array}$ & Metodologia & $\begin{array}{c}\text { Técnica para confecção do } \\
\text { provisório }\end{array}$ & Resultados \\
\hline $\begin{array}{l}\text { Huetting et } \\
\text { al. }^{3}\end{array}$ & $\begin{array}{l}\text { Avaliar o desempenho } \\
\text { clínico das próteses } \\
\text { dentárias fixas temporárias } \\
\text { à base de PMMA, } \\
\text { confeccionados em CAD- } \\
\text { CAM. }\end{array}$ & $\begin{array}{l}\text { Estudo clínico } \\
\text { observacional } \\
\text { (2C) }\end{array}$ & $\begin{array}{l}\text { Resina em bloco para } \\
\text { CAD-CAM }\end{array}$ & $\begin{array}{l}27 \text { pacientes com } \\
\text { necessidades de coroa fixa e } \\
\text { ponte fixa foram selecionados. } \\
\text { Os preparos foram moldados } \\
\text { de forma convencional e } \\
\text { digitalizados em laboratorial } \\
\text { Um material de cimento } \\
\text { híbrido modificado por resina } \\
\text { (RelyX Unicem) foi usado para } \\
\text { cimentação em um protocolo } \\
\text { convencional. }\end{array}$ & $\begin{array}{l}\text { Os preparos foram digitalizados } \\
\text { e os provisórios foram } \\
\text { projetados e fabricados com } \\
\text { Cerec 3D inLab CAD/CAM. A } \\
\text { cimentação foi realizada com } \\
\text { cimento resinoso ( RelyX } \\
\text { Unicem). }\end{array}$ & $\begin{array}{l}\text { Durante o período de observação, } 11 \\
\text { complicações foram encontradas em } 9 \text { das } \\
45 \text { restaurações de PMMA: } 4 \text { perdas de } \\
\text { retenção e } 5 \text { fraturas completas. Três dos } \\
\text { oito provisórios em cantiléver tiveram que } \\
\text { ser removidos dentro de } 8 \text { meses, } \\
\text { apresentando alta taxa de falha. } \\
\text { Os provisórios mostraram uma taxa de } \\
\text { sobrevivência de } 90,4 \% \text {. } \\
\text { Resina PMMA pode ser usada com sucesso } \\
\text { para provisórios de longo prazo com } \\
\text { próteses parciais fixas de } 3 \text { a } 4 \text { unidades em } \\
\text { um período de pelo menos um ano. }\end{array}$ \\
\hline
\end{tabular}

Fonte: Os autores (2021). 
Dentre as técnicas diretas para confecção de provisórios em prótese fixa, pode-se destacar a Adaptação da Faceta de Estoque sobre o preparo ou para casos de dentes tratados endodonticamente, a Resina adaptada ou bolinha para dentes posteriores. Quanto à técnica indireta, o Molde ou Matriz em silicone apresenta-se em ênfase. ${ }^{4}$ Estes protocolos para execução de provisórios são bastante executados na clínica diária e são detalhados nas Figuras 2, 3, 4, 5. Por fim, a Figura 6 mostra a evolução da técnica com coroas provisórias confeccionadas em CAD/CAM com blocos de polímero ${ }^{3}$, em um caso de aumento de dimensão vertical.

Figura 2. Adaptação da Faceta de Estoque (sobre o preparo): A-Seleção do cor dente artificial; B, C-Determinação do tamanho; D-Marcação cervical para desgaste; E, F-Desgaste palatina com broca maxicut; G-Isolamento do preparo com vaselina sólida; H-Aplicação de resina acrílica sobre preparo pela Técnica de Nealon; I-Aplicação de resina acrílica sobre a porção interna da faceta; J-Posicionamento da faceta sobre o preparo; K- Aplicação de resina acrílica sobre a porção palatina; L- Provisório pós polimerização da resina, desse modo observa-se a cópia do término cervical e excessos; M-Reembasamento do provisório sobre o preparo, a fim de obter melhor adaptação; N-Demarcação do término cervical; O-Remoção de excessos; P-Ajuste oclusal em máxima intercuspidação habitual, lateralidade e protrusão; Q-Avaliar ponto de contato; R, S-Polimento mecânico com borrachas siliconadas (verde, cinza, amarela) e escovas (schot brite, pelo de cabra, pelo de algodão), respectivamente; T, U-Vista palatina e vestibular do provisório, respectivamente
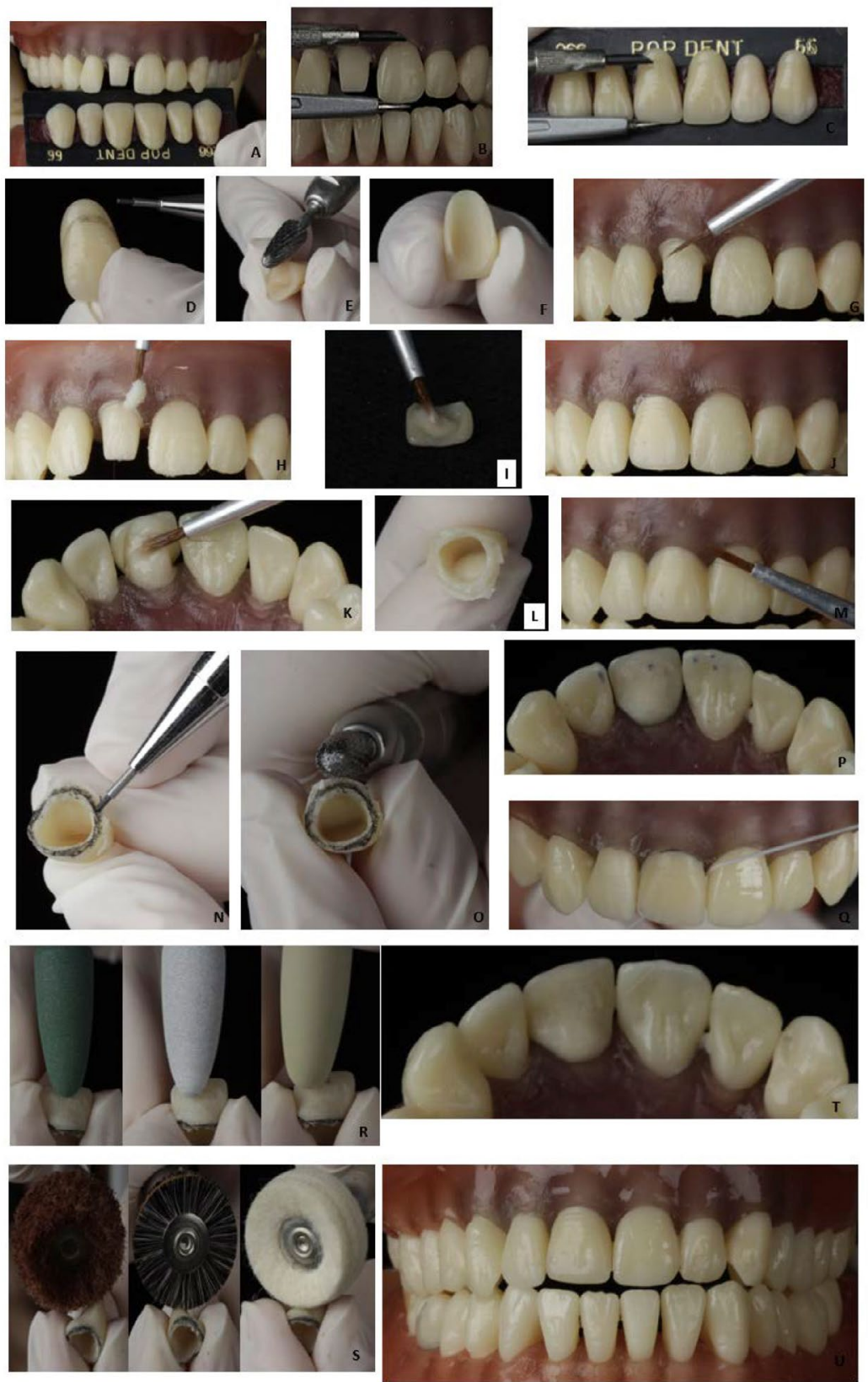

Fonte: Os autores (2021). 
Figura 3. Adaptação da Faceta de Estoque (em dente tratado endodonticamente): A-Dente tratado endodonticamente com mínimo remanescente coronário; B-Pinos provisórios e faceta de estoque já preparada; C-Posicionamento da faceta de estoque sobre o preparo dental; D-Desgaste sobre o pino para favorecer a retenção da resina; E-Teste do pino sobre o contudo; F-Posicionamento vestibular da porção coronária do pino e desgaste para favorecer o assentamento da faceta de estoque; G- Posicionamento da faceta de estoque; H-Isolamento dos dentes adjacentes e do contudo com auxílio de lima endodôntica envolvida com algodão; preparo com vaselina sólida; I- Aplicação de resina acrílica sobre o pino; J-Inserção do pino (com resina) sobre o conduto, a fim de individualiza-lo; K-Posicionamento da faceta de estoque sobre o conjunto pino e preparo dental, como também preenchimento com resina na porção palatina do provisório; L-Captura do pino pelo provisório e Desgaste; M-Provisório com vista interior mostrando o pino, finalizado pós acabamento e polimento mecânico; N-Conjunto pino e provisório; O-Vista palatina do provisório; P-Vista vestibular do provisório em máxima intercuspidação habitual
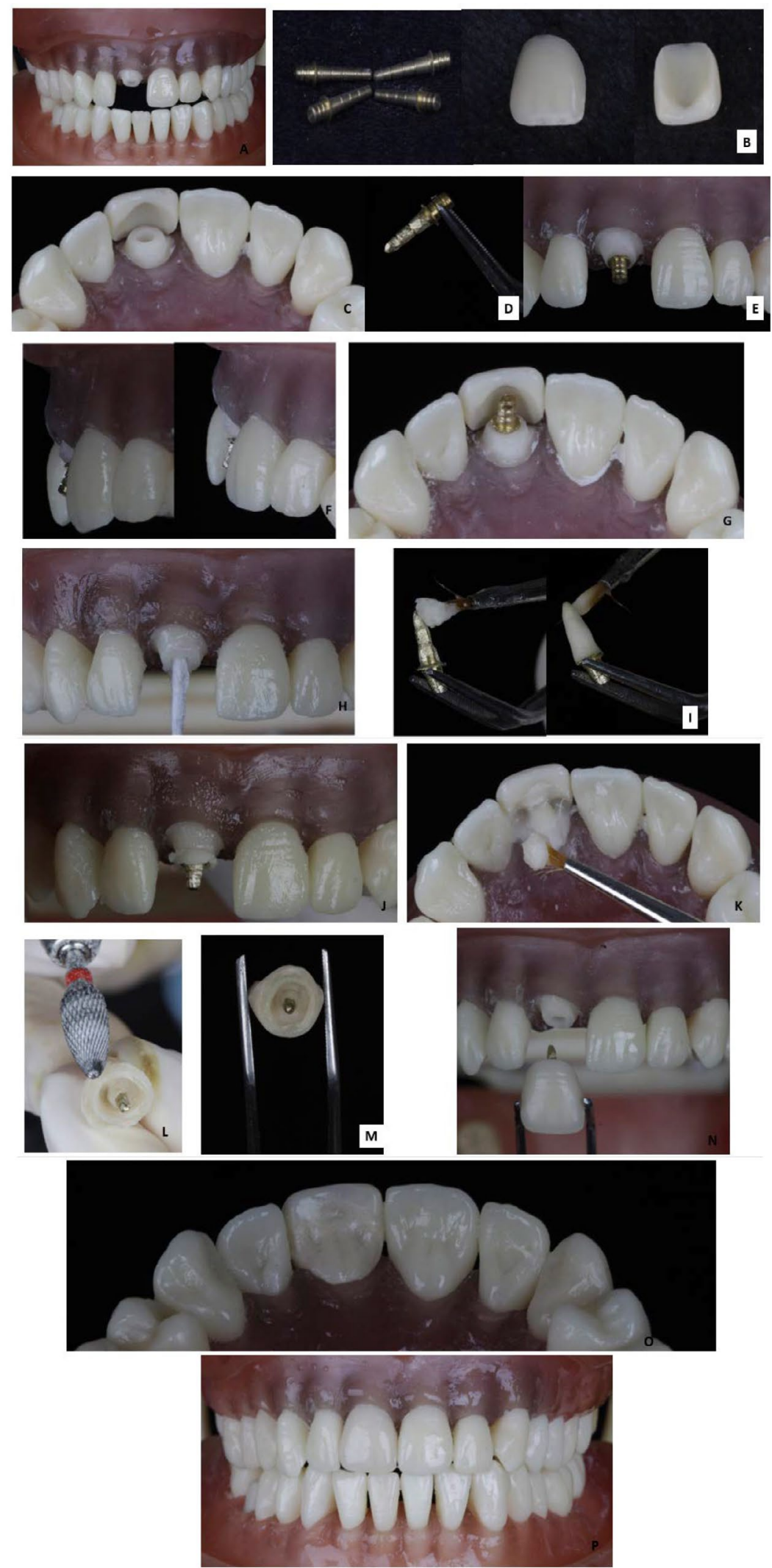

Fonte: Os autores (2021). 
Figura 4. Resina adaptada / bolinha: A-Preparo para coroa total dente posterior; B, C- Isolamento do preparo e dente antagonista com vaselina sólida, respectivamente; D- Homogenização do pó ao líquido; E-Fase arenosa da resina acrílica; F-Fase Fibrosa da resina acrílica; G-Fase plástica da resina acrílica; H-Confecção de uma "bolinha"; I-Adaptação da resina acrílica sobre preparo; J-Fechamento em máxima intercuspidação habitual, a fim de comprimir a resina sobre o preparo e também a resina pode ser adaptada na região vestibular, palatina ou lingual; K-Aspecto da edentação do dente antagonista sobre a resina; L- Provisório pós polimerização da resina, desse modo observa-se a cópia do término cervical e excessos; M-Remoção dos excessos com broca maxicut; N,O-Demarcação da anatomia dental para ser esculpida sobre a resina com brocas em peça reta; P,Q,R,S- Após o reembasamento do provisório, ajuste proximal e oclusal, e sequência do polimento mecânico; observa-se o provisório numa vista oclusal, lingual, vestibular e em oclusão com o arco antagonista, respectivamente
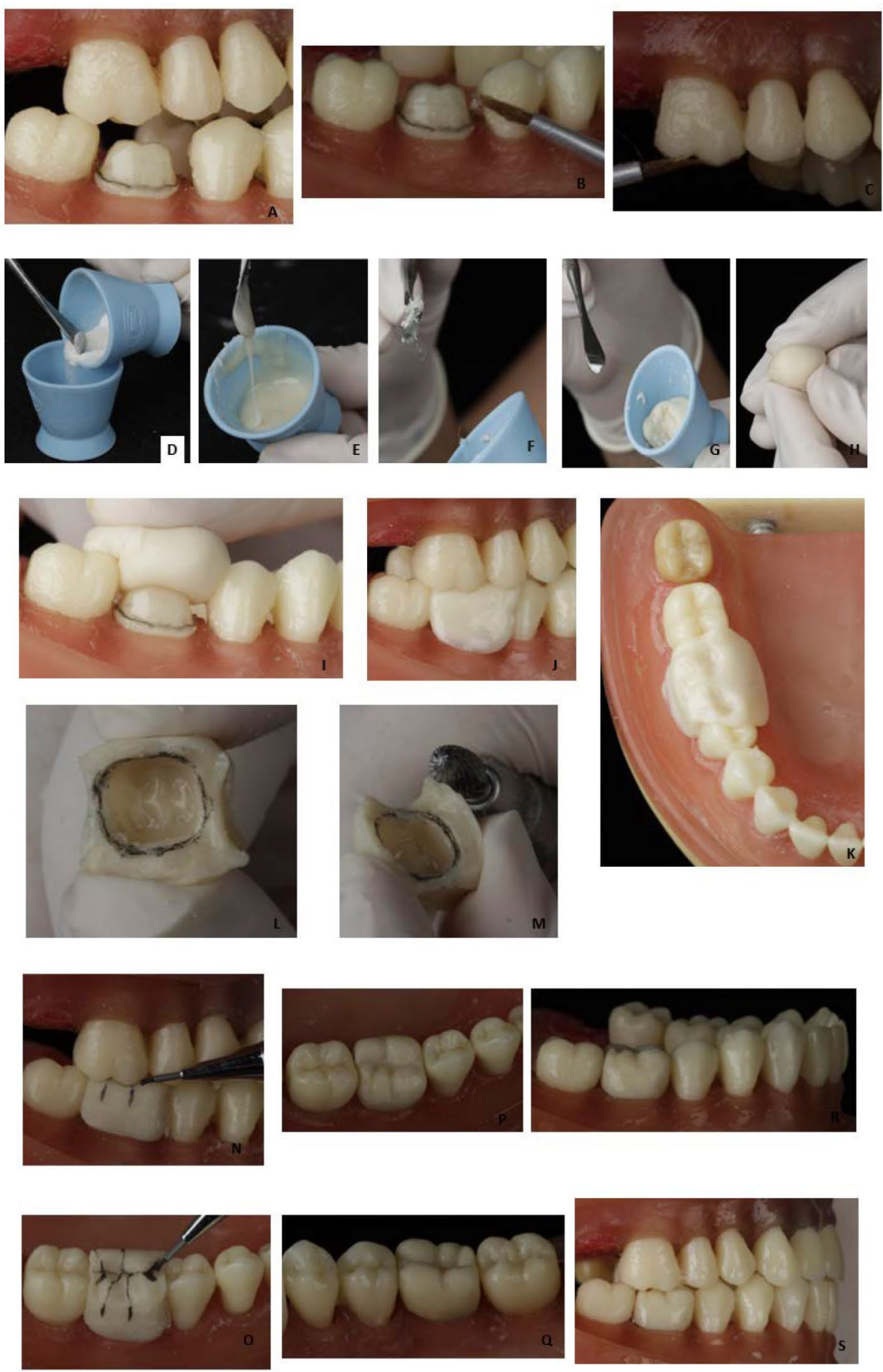

Fonte: Os autores (2021). 
Figura 5. Molde / Matriz em silicone: A-Matriz em silicone pesado foi obtido a partir de um enceramento em modelo em gesso; B-Deposição da resina acrílica pela Técnica de Nealon sobre a matriz; C- Preenchimento da matriz com resina acrílica; D-Posicionamento da matriz sobre o preparo dental, que foi previamente isolado com vaselina sólida; E-Polimerização da resina acrílica; F-Remoção do provisório; G-Provisório e excessos; H- Remoção dos excessos com broca maxicut; I-Vista interna do provisório; J-Aplicação de resina sobre o término cervical, para fins de Reembasamento; K-Aplicação de resina pela Técnica de Nealon sobre a região cervical, para fins de Reembasamento; L- Após o ajuste proximal e oclusal e polimento mecânico, observa-se o provisório numa vista oclusal; M-Provisório em oclusão com o arco antagonista


Fonte: Os autores (2021).

Figura 6. CAD/CAM: A-Conjunto de provisórios; B-Situação de perda de dimensão vertical e desgaste dental excessivo; C-Provisórios em posição
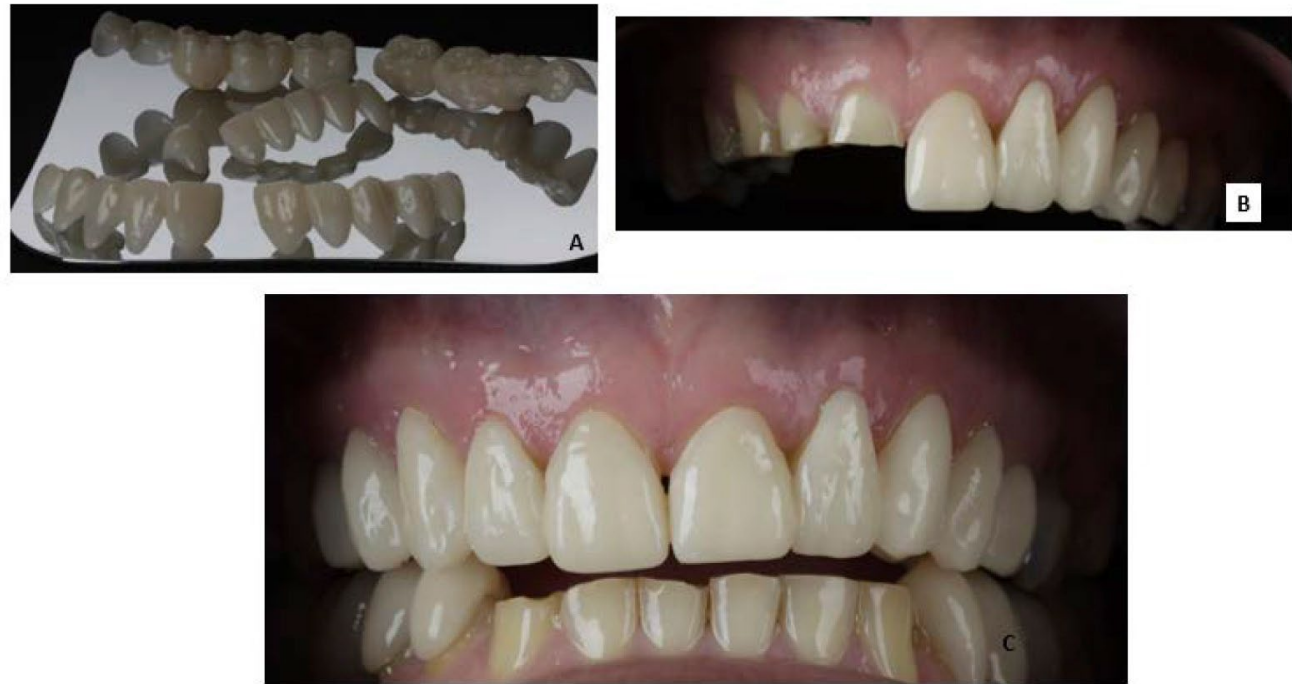

Fonte: Os autores (2021). 


\section{Discussão}

Os estudos revisados abordaram a aplicação de diferentes materiais e técnicas para confecção dos provisórios, assim as pesquisas laboratoriais foram prevalentes entre tais estudos. Desse modo, os testes de resistência mecânica estiveram presentes na metodologia empregada em todos os estudos de laboratório. Observou-se uma heterogeneidade entre objetos de estudos e variáveis, destacando-se o uso de distintos polímeros, técnicas para confecção e adição do reforço.

Os polímeros achados na literatura revisada foram Autopolimerizável (bis-acrílica) ${ }^{8,9,12}$; Dupla Cura, Fotopolimerizável12; A Autopolimerizável (convencional) ${ }^{10,15}$; Termoplástica ${ }^{10}$ e Resina em bloco para CADCAM. ${ }^{6}$ As resinas bis-acrílicas apresentaram melhor desempenho mecânico comparado as resinas convencionais., 9 Pois os provisórios confeccionados com as resinas convencionais falhavam durante o enveIhecimento artificial. 9 Quanto à manipulação, as resinas de dupla cura e fotopolimerizáveis apresentaram difícil manuseio comparado às resinas bis-acrílicas; embora tenham excelentes propriedades mecânicas como integridade, pontos de contato oclusais e espaçamento interdental. ${ }^{12}$ As resinas bis-acrílicas apresentam grandes vantagens no que se refere a facilidade de manipulação, proporção mais precisa, pouco ou nenhum odor, baixa reação exotérmica, relativa adaptação marginal, resistência e estética. $\frac{16}{}$

O provisório confeccionado em CAD/CAM pode ser usado com sucesso a longo prazo com próteses parciais fixas de 3 a 4 unidades em um período de pelo menos um ano, conforme o estudo clínico de Huetting et al.6. Porém, o mesmo estudo em questão relatou fraturas totais dos provisórios, as quais podem ter ocorrido devido aos provisórios em cantiléver. E a longevidade pode ser explicada pela cimentação resinosa que favorece a permanência da peça em posição pela adesão a estrutura dental. ${ }^{6}$ Essa técnica vem ganhando espaço pela facilidade de obtenção principalmente de provisórios múltiplos, como mostrada na Figura 6. Bem como as demais técnicas apresentadas, são comuns na prática clínica e são reproduzidas nas escolas odontológicas durante formação do cirurgião-dentista. Embora existam vários outros métodos para confecção de provisórios em prótese fixa, são raras as literaturas que demonstram um passo a passo detalhado, fator este que desfavorece o desenvolvimento da habilidade do profissional. Nos artigos revisados, as técnicas encontradas foram uso da matriz em acetato ${ }^{12}$, molde em silicone ${ }^{2,10,15}$; molde de aço especifico para uma condição laboratorial não sendo representativo para prática clínica ${ }^{8}$, CAD/CAM. $\underline{6}$

O uso do reforço associado a materiais de provisórios como resinas convencional e bis-acrílica demonstraram resistência à fratura significativamente maior comparado a ausência deles. Dentre os reforços estudados, a tenacidade à fratura do fio metálico e da fibra de vidro associados à resina foram semelhantes, enquanto a fibra de polietileno não foi significativa entre os materiais de provisório. Resultado que também corrobora com a pesquisa de Nohrstrom; Vallittu; Urpo $\frac{15}{}$, que adiciona que 0 comprimento do provisório e a quantidade de fibras afetam significativamente a resistência à fratura. Dessa forma, em provisórios de grande extensão, a ação do reforço da fibra de vidro torna-se mais necessário a longo prazo. No estudo de Pfeiffer e Grube $^{10}$ uma resina impregnada por fibra apresentou os melhores resultados de resistência a fratura comparado aos polímeros associados a fibras não impregnadas, resina autopolimerizável (convencional) e termoplástica. Além disso, a resistência à fratura de provisórios reforçados não foi afetada pela altura do pôntico. Vale salientar, que todas as evidências sobre o uso de reforço em materiais provisórios foram de estudos laboratoriais com variação de teste, envelhecimento e corpos de prova. Porém, em todos estes estudos revisados o reforço favoreceu as propriedades mecânicas das resinas para uso temporário em prótese fixa.

Os raros estudos clínicos selecionados confirmaram o que a literatura já divulgava, que o índice de placa é maior sobre as restaurações temporárias que no dente adjacente natural; embora o índice de sangramento gengival não apresentou mudança significante. ${ }^{12}$ Apenas 2 casos apresentaram coloração insatisfatória ${ }^{12}$, perda de retenção ${ }^{6}$ e fraturas totais ou parciais ${ }^{6,12}$ foram observadas. Mesmo com todas estas complicações, os pacientes avaliaram os materiais temporários como satisfatórios. ${ }^{12}$ 
Logo, é necessária uma baixa rugosidade superficial da resina para evitar acúmulo de biofilme, e assim ser instalada uma condição de inflamação gengival ou desenvolvimento de lesões cariosas. ${ }^{17}$ Contudo essas patologias são recorrentes quando o polimento é negligenciado. A defasagem da coloração é uma desvantagem dos polímeros temporários, que ainda não foi superada e dificulta a permanência do provisório a longo prazo em meio oral. A perda de retenção e fraturas podem ser representadas por distintos fatores, como o fracasso da cimentação provisória, preparo dental inadequado e/ou ajuste oclusal deficiente. ${ }^{18}$

Esta revisão da literatura apresenta como limitações, poucos estudos clínicos com elevada evidência científica o que nos proporciona indícios à extrapolação desses resultados para clínica odontológica, também não foram mostradas todas as técnicas para confecção dos provisórios. Houve uma dificuldade em confrontar os achados; por serem muitos distintos em vários aspectos como tipo de estudo, materiais, corpos de prova, ensaios mecânicos e de envelhecimento. Entretanto, os achados desta revisão permitem aos clínicos ter evidências quanto ao uso de materiais resinosos e seu desempenho mecânico. Favorece a prática clínica, por apresentar um guia para realização de diferentes técnicas para confecção de provisórios.

Novos estudos clínicos com materiais provisórios devem ser propostos que avaliem a habilidade do profissional em diferentes técnicas, métodos de polimento juntamente com a resposta periodontal, o uso de reforço em prótese fixa extensas sobre dente e sobre implante. Criar novas gerações de matérias temporários com propriedades mecânicas e ópticas melhores, através de manufaturas computacionais

\section{Considerações finais}

A literatura revisada apresentou diversos materiais provisórios disponíveis no mercado. Os estudos que avaliaram resina bis-acrílica apresentaram essa resina com qualidade superior à resina convencional quanto a resistência mecânica à fratura. Assim como a presença de reforço favorece o desempenho mecânico dos polímeros. As técnicas para confecção de provisórios em prótese fixa relatadas na literatura pesquisada foram o uso do molde em silicone, matriz em acetato e CAD/CAM. E as técnicas mais comuns de serem executadas na clínica diária foram adaptação da faceta de estoque (sobre o preparo e dente tratado endodonticamente), resina adaptada ou bolinha e molde ou matriz em silicone.

\section{Contribuição dos autores}

Queiroz ACS, Gomes RL participaram da revisão de literatura e escrita do artigo. Figueiredo VMG participou da escrita artigo e captura das imagens. Rodrigues GMF participou da captura das imagens.

\section{Conflitos de interesses}

Nenhum conflito financeiro, legal ou político envolvendo terceiros (governo, empresas e fundações privadas, etc.) foi declarado para nenhum aspecto do trabalho submetido (incluindo, mas não se limitando a subvenções e financiamentos, participação em conselho consultivo, desenho de estudo, preparação de manuscrito, análise estatística, etc.).

\section{Referências}

1. Ireland MF, Dixon DL, Breeding LC, Ramp MH. In vitro mechanical property comparison of four resins used for fabrication of provisional fixed restorations. J Prosthet Dent 1998;80(2):158-62. https://doi.org/10.1016/S0022-3913(98)70104-0

2. Lang R, Rosentritt M, Leibrock A, Behr M, Handel G. Colour stability of provisional crown and bridge restoration materials. $\mathrm{Br}$ Dent J. 1998;185(9):468-71. https://doi.org/10.1038/sj.bdj.4809839

3. Favarão J, Zanini MM, Daga AM, Camilotti V, Mendonça MJ. Influência de desinfetantes bucais sobre a dureza de superfície de resinas para provisórios. Prosthes. Esthet. Sci [Internet]. 2018:6671. Disponível em: https://pesquisa.bvsalud.org/portal/resource/ pt/biblio-906957

4. Neppelenbroek KH, Lopes JF, Silva RH, Segalla JC. A importância das próteses provisórias. Rev. gaúch. odontol [Internet]. 2003;51(1):50-3. Disponível em: http://www.revistargo.com.br/ viewarticle.php?id=420

5. Scotti R, Mascellani SC, Forniti F. The in vitro color stability of acrylic resins for provisional restorations. Int J Prosthodont. 1997;10(2):164-8. Citado em: PMID: 9206457 
6. Huettig F, Prutscher A, Goldammer C, Kreutzer CA, Weber H. First clinical experiences with CAD/CAM-fabricated PMMA-based fixed dental prostheses as long-term temporaries. Clin Oral Investig. 2016;20(1):161-8. https://doi.org/10.1007/s00784-0151475-7

7. Brännström M. Reducing the risk of sensitivity and pulpal complications after the placement of crowns and fixed partial dentures. Quintessence Int. 1996;27(10):673-678. Citado em: PMID: 9180403

8. Geerts GA, Overturf JH, Oberholzer TG. The effect of different reinforcements on the fracture toughness of materials for interim restorations. J Prosthet Dent. 2008;99(6):461-7. https://doi. org/10.1016/s0022-3913(08)60108-0

9. Lang R, Rosentritt M, Behr M, Handel G. Fracture resistance of PMMA and resin matrix composite-based interim FPD materials. Int J Prosthodont. 2003;16(4):381-4. Citado em: PMID: 12956492

10. Pfeiffer P, Grube L. Effect of pontic height on the fracture strength of reinforced interim fixed partial dentures. Dent Mater. 2006;22(12):1093-7. https://doi.org/10.1016/j.dental.2005.09.003

11. von Fraunhofer JA, Suchatlampong C. The surface characteristics of denture base polymers. J Dent. 1975;3(3):105-9. https://doi.org/10.1016/0300-5712(75)90060-3

12. Luthardt RG, Stössel M, Hinz M, Vollandt R. Clinical performance and periodontal outcome of temporary crowns and fixed partial dentures: A randomized clinical trial. J Prosthet Dent. 2000;83(1):32-9. https://doi.org/10.1016/s0022-3913(00)70086-2
13. Miyazaki T, Hotta Y. CAD/CAM systems available for the fabrication of crown and bridge restorations. Aust Dent J. 2011;56(Supl 1):97-106. https://doi.org/10.1111/j.18347819.2010.01300.x

14. Demathé A, Silva ARS, Carli JP, Goiato MC, Miyahara GI. Odontologia baseada em evidências: otimizando a prática e a pesquisa. RFO UPF [Internet]. 2012;17(1): 96-100. Disponível em: http://revodonto.bvsalud.org/scielo.php?pid=S1413$\underline{40122012000100018 \& \text { script }=\text { sci arttext }}$

15. Nohrström TJ, Vallittu PK, Yli-Urpo A. The effect of placement and quantity of glass fibers on the fracture resistance of interim fixed partial dentures. Int J Prosthodont. 2000;13(1):72-8. Citado em: PMID: 11203613

16. Lelis V. Resinas Bisacrílicas: Características das restaurações temporárias [Internet]. Piracicaba: Faculdade de Odontologia de Piracicaba da Universidade Estadual de Campinas; 2014. Disponível em: http://www.bibliotecadigital.unicamp.br/ document/?view=000922199

17. Seabra EJG, Lima IPC, Matsuno PM, Paiva ACS. Rugosidade superficial da resina acrílica frente a quatro diferentes técnicas de polimento. Rev gaúch odontol. [Internet]. 2011;59(1):4550. Disponível em: http://revodonto.bvsalud.org/scielo. php?script=sci_arttext\&pid=S1981-86372011000100007

18. Pegoraro LF, Valle AL, Araújo CRP, Bonfante G, Conti PCR. Prótese fixa: bases para o planejamento em reabilitação oral. São Paulo: Artes Médicas; 2013. 